\title{
8 hrs Safety Evaluation Of A Multi-Pressure Dial In Eyes With Glaucoma: Prospective, Open-Label, Randomized Study
}

This article was published in the following Dove Press journal: Clinical Ophthalmology

\author{
Thomas W Samuelson' \\ Tanner J Ferguson (iD) ${ }^{2}$ \\ Nathan M Radcliffe (iD ${ }^{3}$ \\ Richard Lewis ${ }^{4}$ \\ Justin Schweitzer ${ }^{5}$ \\ Russell Swan ${ }^{5}$ \\ John P Berdahl (iD) \\ 'Minnesota Eye Consultants, Minneapolis, \\ MN, USA; ${ }^{2}$ Cole Eye Institute, Cleveland \\ Clinic, Cleveland, OH, USA; \\ ${ }^{3}$ Department of Ophthalmology, New \\ York Eye and Ear Infirmary of Mount \\ Sinai, New York, NY, USA; ${ }^{4}$ Sacramento \\ Eye Consultants, Sacramento, CA, USA; \\ ${ }^{5}$ Vance Thompson Vision, Sioux Falls, \\ SD, USA
}

Purpose: To investigate the safety and tolerability of the multi-pressure dial with a continuous 8-hr duration in subjects with open-angle glaucoma.

Design: Prospective, controlled open-label, randomized, single site study.

Subjects: Twenty eyes of 10 subjects with open-angle glaucoma were fitted with a multipressure dial and randomized to negative pressure application of $-10 \mathrm{mmHg}$ in one eye for 8 (continuous) hours and ambient atmospheric pressure in the contralateral eye.

Methods: Main safety outcome measures include best-corrected visual acuity (BCVA), intraocular pressure (IOP) changes from baseline after negative pressure application, slit lamp and dilated fundus exam findings, and rate of adverse events. Subjective assessments were administered both hourly during the 8-hr study period and immediately following the study period.

Results: There were no statistically significant changes in IOP, BCVA or TBUT immediately following the 8-hr study period or at the 1 -week follow-up visit. Patient-reported tolerability was favorable with a mean response of $1.8 \pm 0.4$ (scale $\rightarrow 1=$ best, $10=$ worst). Subjects also reported positive interest in the MPD as a glaucoma therapy with a mean response of $1.8 \pm$ 0.5 (scale $\rightarrow 1=$ best, 10 = worst). One adverse event was reported (headache) and resolved at conclusion of the Day 0 visit.

Conclusion: The MPD demonstrated favorable safety with key parameters remaining stable after an 8-hr wear with negative pressure. Negative pressure application through the MPD was well tolerated by subjects enrolled in the study. The favorable findings demonstrate the safety of sustained delivery of negative pressure over a continuous, uninterrupted 8-hr duration.

Keywords: multi-pressure dial, normal-tension glaucoma, open-angle glaucoma, glaucoma treatment

\section{Introduction}

Glaucoma remains a leading cause of blindness worldwide. ${ }^{1}$ Currently, treatment options primarily target the reduction of intraocular pressure (IOP), currently the sole modifiable risk factor associated with the disease. ${ }^{2}$ However, despite the advent of new medical and surgical options, a significant number of patients do not achieve adequate IOP lowering and many still exhibit disease progression despite achieving an individualized "target" IOP. ${ }^{3}$ The mainstay of treatment options includes topical medications, lasers and surgery. While significant innovation has produced improved options for patients, clinicians caring for glaucoma patients continue to seek better options while trying to balance efficacy
Correspondence: Tanner J Ferguson Cole Eye Institute, Cleveland Clinic, Cleveland OH, USA

Email tannerferg@gmail.com 
and safety. Currently, there are no treatment options for glaucoma that are non-laser, non-pharmacological and non-surgical.

In this study, we investigate the use of the multi-pressure dial (Equinox Ophthalmic, Inc., Newport Beach, CA), which is comprised of a pair of goggles that individually enclose the periorbital regions of each eye. Each eye is separately connected to a pressure-modulating pump. Target negative pressure is programmed via software into the handheld device that controls the pump and an individualized pressure value can be created for each periorbital region. With proper fit of the multi-pressure dial (MPD), shown in Figure 1, a negative pressure microenvironment at the programmed target level is established, resulting in a corresponding and immediate lowering of IOP.

The short-term safety of the MPD has been established with key safety parameters remaining unchanged after a 30 -min wear in a prior study by Thompson et al. ${ }^{4}$ The goal of this study is to evaluate safety and tolerability of the MPD for an extended, uninterrupted duration ( $8 \mathrm{hrs})$.

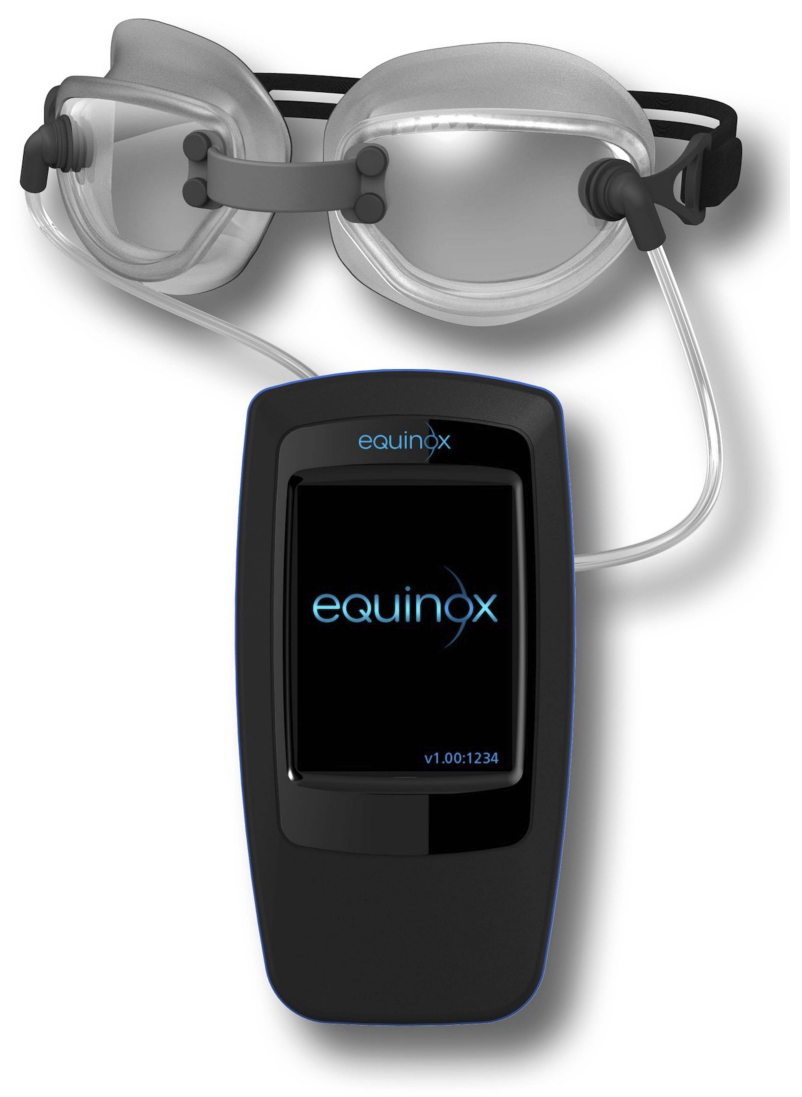

Figure I Multi-pressure dial, which includes the goggles connected to a handheld pressure-modulating pump. This device was worn for the duration of the 8-hr study period in this study.

\section{Methods}

\section{Subjects}

Ten subjects participated in this prospective, open-label, pilot study. One eye of each enrolled subject was randomized to receive negative pressure application of -10 $\mathrm{mmHg}$, while the contralateral eye served as the control, receiving no negative pressure. Subject and demographic characteristics are summarized in Table 1. This protocol was approved by Aspire IRB (Santee, California) as a nonsignificant risk study and was performed at a single site (Sioux Falls, SD). This clinical study was conducted in accordance with the protocol and the principles of the Declaration of Helsinki. Written informed consent was obtained for each subject prior to any study procedures.

Key inclusion criteria were subjects $\geq 18$ years of age with orbital anatomy that permitted a proper seal when the MPD goggles were placed, subjects capable of tolerating IOP measurements, and a documented diagnosis of open-angle glaucoma, glaucoma suspect or ocular hypertension. Subjects with the following surgical history were permitted to enter the study: refractive (eg, PRK, LASIK, SMILE), cataract surgery, cataract surgery with minimally invasive glaucoma surgery (MIGS) and standalone MIGS procedures. Exclusion criteria included the presence or history of any eye disease or condition that could

Table I Baseline Characteristics

\begin{tabular}{|l|l|}
\hline Parameter & \\
\hline Age, years (Mean, SD) & $65.2 \pm 12.5$ \\
Gender (M/F) & $5 \mathrm{M} / 5 \mathrm{~F}$ \\
Ethnicity & $100 \%$ White \\
BCVA (mean \pm SD) & \\
Study eye & $0.00 \pm 0.15$ \\
Fellow eye & $-0.01 \pm 0.10$ \\
IOP, mean \pm SD, range & \\
Study eye (mmHg) & $15.75 \pm 4.4, \quad \mathrm{II}-24$ \\
Fellow eye (mmHg) & $15.40 \pm 4.4, \mathrm{II}-23$ \\
Visual Field Parameters & \\
Study eye & \\
VFI (\%), mean $\pm \mathrm{SD}$ & $0.9 \pm 0.2$ \\
Mean deviation (dB), mean $\pm \mathrm{SD}$ & $-3.4 \pm 7.0$ \\
Pattern standard deviation (dB), mean $\pm \mathrm{SD}$ & $3.6 \pm 3.2$ \\
Fellow eye & \\
VFI (\%), mean $\pm \mathrm{SD}$ & $0.9 \pm 0.2$ \\
Mean deviation (dB), mean $\pm \mathrm{SD}$ & $-2.6 \pm 6.1$ \\
Pattern standard deviation (dB), mean $\pm \mathrm{SD}$ & $2.5 \pm 3.9$ \\
Cup-disc ratio, mean $\pm \mathrm{SD}$ & \\
Study eye & $0.6 \pm 0.2$ \\
Fellow eye & $0.6 \pm 0.2$ \\
\hline
\end{tabular}

Abbreviations: BCVA, best-corrected visual acuity; VFI, visual field index; SD, standard deviation; $\mathrm{dB}$, decibels. 
interfere with the assessment of the study results or subject safety. Subjects with macular degeneration, untreated retinal detachment or other fundus findings that could inhibit visualization of the retina in either eye, eyelid edema or conjunctival chemosis in either eye, or history of allergy to any of the testing materials (e.g., silicone) were excluded. Women who were pregnant or lactating during the time of the study were also excluded.

\section{Study Design}

Each subject was screened for proper fit of the MPD goggles to ensure a proper seal could be achieved and maintained. Subjects who passed screening were enrolled in the study and one eye of each enrolled subject was randomized to negative pressure application. All baseline testing occurred prior to exposure to the study device. There were no screen failures.

All subjects underwent a baseline ophthalmological exam. The exam included the following diagnostic tests: best-corrected visual acuity (BCVA), manifest refraction, cup-disc ratio, tear break-up time (TBUT), OCT of the retinal nerve fiber layer (RNFL) and intraocular pressure (IOP). In addition, a comprehensive slit lamp and dilated fundus examination were performed. Cup-disc ratio was subjectively measured during dilated fundus examination.

IOP measurements were obtained via Goldmann applanation tonometry (GAT). These measurements occurred at baseline prior to wear of the MPD, immediately after the study period and at the 1-week follow-up visit. After baseline testing was completed, the study period was initiated with application of negative pressure with the MPD. The MPD collectively includes a pair of goggles that individually enclose each periorbital region of each eye with separate connections to a regulated pump. The MPD goggles were worn by the subject for the entire, uninterrupted duration of the study period. Negative pressure was set at $-10 \mathrm{mmHg}$ (study eye only) for $8 \mathrm{hrs}$ ( \pm 30 mins) total wear time; minimum wear time was $4 \mathrm{hrs}$. Subjects were permitted to discontinue the study at any time.

For this study, the visits included screening, Day 0 and week 1 (6-8 days). "Day 0" was used to denote the day the 8$\mathrm{hr}$ wear time occurred. Screening and Day 0 (testing) were permitted on the same day. At the week 1 visit, baseline testing was repeated including IOP, BCVA, OCT and subjects were also assessed for adverse events that may have occurred in the one week following the $8 \mathrm{hrs}$ application of negative pressure.

In this study, two subjective assessments were performed including a perception questionnaire provided hourly during the study protocol as well as an initial use questionnaire that was provided after the testing period. The hourly perception questionnaire consisted of various questions regarding the tolerability of the goggles and associated components. The scale ranged from 1 to 10 with $1=$ best, $10=$ worst. The initial use questionnaire aimed to collectively evaluate the comfort of the device and its components after the 8-hr study period and used a scale of $1-10$ with $1=$ most comfortable and $10=$ not comfortable.

\section{Statistical Methods}

Measurements of IOP via Goldmann applanation tonometry, tear film breakup time (TBUT) and best-corrected visual acuity (BCVA) were analyzed to compare baseline values to various time points including immediately post-study and 1-week poststudy.

A paired, parametric sample $t$-test was employed as part of the analysis with the baseline used as the initial state and each study point analyzed individually as end points. The mean of the difference was tested against zero, where the null hypothesis is that the mean is equal to zero and the alternative hypothesis is that the mean is not equal to zero. An $\alpha$ level of 0.05 was considered statistically significant. All statistical analyses were performed using SciPy python 3.6.7 statistical software.

\section{Subject Demographics}

This study evaluated 20 eyes from 10 subjects, including 10 study eyes and 10 control eyes. The contralateral eye in each subject was used as the control. The mean age of the subjects was $65.2 \pm 12.5$ years. Of the 10 subjects, half were female. This demographic information is included with other preoperative parameters including BCVA, cup-disc ratio, IOP and visual field characteristics in Table 1.

The IOP results are demonstrated in Figure 2. At baseline, IOP measurements were performed and obtained via

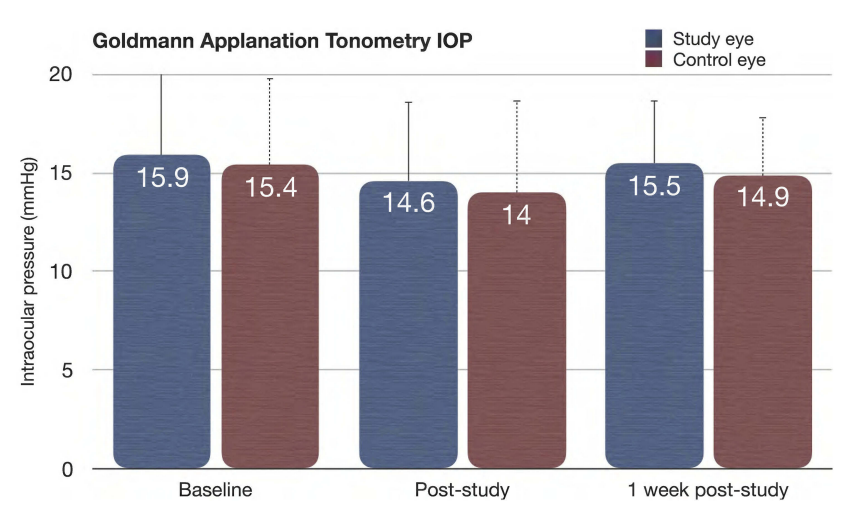

Figure 2 This graph demonstrates the mean IOP values at each time point and were collected via Goldmann applanation tonometry (GAT). These measurements were taken without the MPD. The error bars represent standard deviation (SD). 
Goldmann applanation tonometry (GAT). Prior to placing the MPD, the mean baseline IOP value of the study $(n=10)$ and fellow eyes $(n=10)$ was $15.8 \pm 4.4 \mathrm{mmHg}$ and $15.4 \pm 4.4$ $\mathrm{mmHg}$, respectively. After the continuous, 8-hr study period with the MPD, the MPD goggles were removed and IOP measurements were repeated. Immediately after the 8-hr study duration, repeat measurements were $14.6 \pm 4.0$ $(\mathrm{p}>0.05) \mathrm{mmHg}$ in the study eye and $14.0 \pm 4.7 \mathrm{mmHg}$ $(p>0.05)$ in the fellow eye (which did not receive negative pressure). At the 1-week follow-up visit, IOP measurements were repeated and the mean 1 -week IOP was $15.5 \pm 3.2$ $(\mathrm{p}>0.05)$ and $14.9 \pm 2.9(\mathrm{p}>0.05)$ in the study and control eyes, respectively. There were no intraocular pressure spikes ( $\geq 10 \mathrm{mmHg}$ ) above baseline in either group at any time.

For the investigation of visual changes, best-corrected visual acuity (BCVA) values were collected at baseline, immediately after the study period and 1 week later. At baseline, the mean BCVA (LogMAR) of the study and fellow eyes of the subjects was $0.00 \pm 0.15$ and $-0.01 \pm 0.1$, respectively. After the 8 -hr time period on day 0 , the mean value was $-0.03 \pm 0.08(\mathrm{p}>0.05)$ in the study group and $-0.01 \pm 0.09(\mathrm{p}>0.05)$ in the control group. At the 1-week follow-up, the mean BCVA was $-0.02 \pm 0.08(\mathrm{p}>0.05)$ and $-0.02 \pm 0.09(\mathrm{p}>0.05)$ in the study and control groups, respectively.

To evaluate the impact of the 8-hr study period on the ocular surface, TBUT measurements were obtained at baseline, immediately post-study and at the 1-week follow-up. At baseline, the mean TBUT of the study and fellow eyes was $8.5 \pm 2.3$ and $8.1 \pm 2.1$ seconds (s), respectively. Immediately after the 8 -hr wear period, the mean value was $8.2 \pm 2.3 \mathrm{~s}$ in the study eye and $6.7 \pm 3.0 \mathrm{~s}$ in the fellow eyes. At the 1-week follow-up, the mean TBUT values of the study and fellow eyes were $9.2 \pm 1.1 \mathrm{~s}$ and $8.7 \pm 2.1 \mathrm{~s}$, respectively. The values immediately post-study and at the 1-week follow-up were not significantly different from baseline in either group ( $\mathrm{p}>0.05)$.

There were no observed differences from baseline in either the study or fellow eye in the slit lamp or dilated fundus examination after the 8-hr study duration. In addition, at the one-week visit, there were no new or abnormal slit lamp or dilated fundus exam findings observed. OCT RNFL measurements were also collected at baseline in addition to the 1-week follow-up visit. At baseline, the mean RNFL global thickness was $81.4 \mu \mathrm{m}$ in the study eye and $84.4 \mu \mathrm{m}$ in the fellow eye. At the 1-week follow-up, the mean global RNFL thickness slightly increased in both eyes to $83.9 \mu \mathrm{m}$ in the study eye and $85.1 \mu \mathrm{m}$ in the fellow eye but the difference was not statistically significant $(\mathrm{p}>0.05)$.

\section{Subjective Assessment}

This study included two subjective assessments. The first subjective questionnaire was administered hourly during the 8-hr study period; the scale used for this assessment was $1=$ best, $10=$ worst. The overall mean value for tolerating the MPD was $1.8 \pm 0.4$. For receptiveness towards the MPD as a glaucoma therapy, the mean value was $1.8 \pm 0.5$. When asked about interest in continuing the treatment, the mean response was $1.2 \pm 0.3$. For the perception questionnaire administered hourly, the data and questions included are shown in Table 2.

Table 2 This Table Demonstrates The Results From The Hourly Questionnaire Administered During The 8-hr Study Period. For This Assessment, The Scale Was I=Best, 10=Worst

\begin{tabular}{|c|c|c|c|c|c|c|c|c|c|}
\hline \multicolumn{10}{|c|}{ Hourly Questionnaire - Administered Hourly During 8-hr Study Period } \\
\hline \multirow[t]{2}{*}{ Question } & \multicolumn{9}{|c|}{ Response (Mean, SD) Scale: I=Best, $10=$ Worst } \\
\hline & $\begin{array}{l}\text { Hour } \\
\text { I }\end{array}$ & $\begin{array}{l}\text { Hour } \\
2\end{array}$ & $\begin{array}{l}\text { Hour } \\
3\end{array}$ & $\begin{array}{l}\text { Hour } \\
4\end{array}$ & $\begin{array}{l}\text { Hour } \\
5\end{array}$ & $\begin{array}{l}\text { Hour } \\
6\end{array}$ & $\begin{array}{l}\text { Hour } \\
7\end{array}$ & $\begin{array}{l}\text { Hour } \\
8\end{array}$ & Total \\
\hline How are you tolerating the multi-pressure dial? & $2.1 \pm 1.9$ & $2.3 \pm 1.8$ & $2.3 \pm 2.8$ & $1.4 \pm 0.9$ & $1.6 \pm 0.9$ & $1.6 \pm 0.9$ & $1.5 \pm 0.9$ & $1.6 \pm 1.1$ & $1.8 \pm 0.4$ \\
\hline How Comfortable/uncomfortable is the MPD? & $2.1 \pm 1.9$ & $2.1 \pm 2.1$ & $2.2 \pm 2.8$ & $1.7 \pm 0.9$ & $1.8 \pm 0.8$ & $1.8 \pm 1.2$ & $1.5 \pm 0.9$ & $1.7 \pm 1.1$ & $1.9 \pm 0.3$ \\
\hline How acceptable was the MPD negative pressure? & $1.3 \pm 0.7$ & $1.9 \pm 2.2$ & $2.1 \pm 2.8$ & $1.2 \pm 0.4$ & $1.3 \pm 0.5$ & $1.4 \pm 1.0$ & $1.3 \pm 0.7$ & $1.3 \pm 0.7$ & $1.5 \pm 0.3$ \\
\hline $\begin{array}{l}\text { What is the likelihood of you wearing the device } \\
\text { almost every night? }\end{array}$ & $2.2 \pm 1.7$ & $2.0 \pm 1.9$ & $2.2 \pm 2.8$ & $1.3 \pm 0.7$ & $1.4 \pm 1.0$ & $1.1 \pm 0.3$ & $1.3 \pm 0.7$ & $1.1 \pm 0.3$ & $1.6 \pm 0.5$ \\
\hline $\begin{array}{l}\text { What is your attitude towards MPD as a glaucoma } \\
\text { therapy? }\end{array}$ & $2.6 \pm 1.7$ & $2.2 \pm 1.8$ & $2.3 \pm 2.9$ & $1.6 \pm 1.0$ & $1.7 \pm 0.9$ & $1.3 \pm 0.7$ & $1.3 \pm 0.5$ & $1.2 \pm 0.7$ & $1.8 \pm 0.5$ \\
\hline $\begin{array}{l}\text { How do you feel about continuing or stopping the } \\
\text { therapy? }\end{array}$ & $1.1 \pm 0.3$ & I. $4 \pm 0.4$ & $1.9 \pm 2.9$ & $1.0 \pm 0.0$ & $1.0 \pm 0.0$ & $1.1 \pm 0.3$ & I.I \pm 0.4 & $1.1 \pm 0.3$ & $1.2 \pm 0.3$ \\
\hline
\end{tabular}


To collectively evaluate the comfort and tolerability of the goggles, a subjective questionnaire was administered following the 8-hr study period to conclude day 0 of the study. On a scale of 1-10, subjects were asked to rate the comfort and tolerability of the goggles with $1=$ most comfortable and $10=$ not comfortable. The mean response pertaining to comfort of the goggles was $2.8 \pm 2.8$. These results are shown in Table 3.

All but one subject successfully completed the entire 8$\mathrm{hr}$ study period. There was one device-related adverse event reported during the study period; one subject reported a headache that occurred during the 3rd hour of the study period on Day 0. Review of the event indicated that the MPD head strap was inadvertently positioned too tightly on the subject's head when in use. The subject removed the device but remained in clinic under observation until the conclusion of the 8 - $\mathrm{hr}$ study period and the adverse event was resolved by the conclusion of the study day.

\section{Discussion}

The mainstay of open-angle glaucoma treatment includes therapies that target intraocular pressure reduction. ${ }^{3}$ The introduction of MIGS (minimally invasive glaucoma surgery) has filled a gap that existed between medical therapies and more aggressive filtering procedures (e.g., trabeculectomy, tube shunt, etc.). ${ }^{5}$ In addition, innovation has occurred in the medical treatment space with new topical treatment options recently introduced to the market. ${ }^{6}$ Despite the advent of new technology and expanded number of treatment options, all of these treatments still have accompanied risk and may also carry side effects that compromise a patient's quality of life. Currently, there are no IOP-

Table 3 This Table Demonstrates The Results From The Subjective Questionnaire That Was Administered After The $8 \mathrm{hr}$ Study To Primarily Evaluate Comfort On Day 0

\begin{tabular}{|c|c|}
\hline \multicolumn{2}{|l|}{ Initial Use Questionnaire } \\
\hline Question & $\begin{array}{l}\text { Response } \\
\text { (Mean, SD) }\end{array}$ \\
\hline $\begin{array}{l}\text { Comfort of the goggles, scale of } 1-10 \text { (I=not } \\
\text { comfortable, } 10=\text { comfortable })\end{array}$ & $2.8 \pm 2.8$ \\
\hline $\begin{array}{l}\text { Comfort of the goggles strap, scale of } I-10 \\
(I=\text { not comfortable, } 10=\text { comfortable })\end{array}$ & $1.3 \pm 0.6$ \\
\hline $\begin{array}{l}\text { Comfort of the tubing, scale of } I-10(I=\text { not } \\
\text { comfortable, } 10=\text { comfortable })\end{array}$ & $1.7 \pm 1.3$ \\
\hline
\end{tabular}

Abbreviation: SD, standard deviation. lowering treatments that are non-pharmacologic, non-laser and non-invasive.

Although intraocular pressure-reducing strategies are the foundation of glaucoma treatment, many patients continue to demonstrate disease progression despite reaching their pretreatment "target" value. ${ }^{3}$ There are numerous proposed explanations for this one-dimensional perspective of managing glaucoma, including the recognition of glaucoma as a "two-pressure" disease. One such explanation supporting this may be that optic nerve damage occurs secondary to the imbalance between IOP and cerebrospinal fluid pressure (CSFp) posterior to the optic nerve. This is also known as the translaminar pressure difference (TLPD). This explanation is supported by previous studies that suggest TLPD may play a significant role in the pathogenesis and progression of glaucoma. ${ }^{7-10}$ Furthermore, this imbalance may be compounded with the recognition of nocturnal increase in IOP as well as the known reduction in blood pressure at night. ${ }^{11}$

This study investigated the safety and tolerability of the multi-pressure dial, or MPD, which includes a pair of goggles worn over the periorbital region connected to an intraocular pressure adjusting pump. A prior study primarily evaluating the safety of the device reported favorable safety results evaluating wear of the device for 30 mins. ${ }^{4}$ The MPD creates a negative pressure microenvironment capable of producing a decrease in atmospheric pressure contacting the eye. This atmospheric pressure reduction applied to the eye conveys a corresponding immediate reduction in IOP. By lowering the pressure in the eye relative to other tissues in the body (eg, blood pressure, CSFp) with the MPD, this may facilitate the decoupling of IOP from the CSFp and promote blood flow.

The results of this study suggest that the MPD is safe and tolerable for patients for a continuous period of wear up to $8 \mathrm{hrs}$. The favorable results of the subjective assessments and the isolated, reversible adverse event associated with wear of the MPD promote the safety and tolerability of the device. There were no significant changes in intraocular pressure from baseline to immediately post-study and the 1-week follow-up visit. None of the study subjects experienced any IOP spikes $(\geq 10 \mathrm{mmHg})$ above baseline. Moreover, the study did not contribute to immediate or persistent (1 week) visual changes with no significant difference in BCVA values.

This study is not without limitations. The sample size was small and future studies that include repeated imaging and diagnostic testing (eg, OCT) over a longer-term follow-up will impart additional insight on the impact of 
repeated wear of the MPD. Moreover, studies exploring long-term wear over weeks-months will provide insight on potential concerns related to patient adherence, autoregulatory processes and long-term comfort and tolerability. In addition, it is difficult to discern what negative effects, if any, the goggles may have over an extended period of weeks to months even though the applied negative pressures are small. Despite the limitations, the results of this study are valuable and support future use of the device given the MPD was well tolerated and the safety profile was favorable.

The 8-hr study duration utilized in this present report could simulate the recommended treatment duration for patients in the future. ${ }^{12-14}$ The results of the perception questionnaire indicate that patients would be amenable to wearing the device while sleeping with an average response of $1.6 \pm 0.5$ (scale: $1=$ best, $10=$ worst) to a question assessing the likelihood of wearing the goggles at night. Given that patients are prone to nocturnal IOP increases and decreases in nocturnal blood pressure - both proposed to contribute to the pathophysiology of glaucoma - the MPD could be worn while sleeping, similar to a CPAP machine for OSA. ${ }^{15}$ Moreover, research has demonstrated the impact of nocturnal IOP peaks and fluctuation on progression as well as additional work noting the increased risk in patients with decreased nocturnal ocular perfusion pressure. ${ }^{16-18}$ Notably, the shape and design of the MPD would not preclude a patient from concomitant use of a CPAP. Finally, while additional research is needed, one might speculate that wear of the MPD is particularly important upon awakening in the morning during patient transition from a supine to an upright position. CSF pressure increases during recumbency, an effect that may counterbalance the increase in IOP that also occurs when supine. CSF pressure (CSFp) and IOP are lower when upright; however, in glaucomatous eyes, the change in IOP may persist longer than the change in CSFp when assuming this posture. Wear of the MPD during this time may be particularly beneficial. ${ }^{19,20}$ Other future implications of the MPD yet to be determined include its impact on the episcleral venous pressure (EVP) or aqueous flow across the trabecular meshwork. Future studies investigating regular, daily wear of the device could produce insight into the long-term safety and the potential impact on EVP and trabecular meshwork resistance, which may convey further understanding related to open-angle glaucoma.

In conclusion, the results of this study indicate that the MPD can safely and comfortably worn for an 8-hr time period without deleterious consequences. Utilizing localized, regulated vacuum to modify the pressure in a titratable fashion inside the eye with the MPD is a novel mechanism for IOP reduction and represents a new approach to glaucoma treatment known as multi-pressure glaucoma management. The favorable results of this study support the safety of the device for longer-term wear and promote further use and investigation of the MPD as a potential non-pharmacologic, non-surgical treatment of glaucoma.

\section{Data Sharing Statement}

The data set collected and analyzed for this present study is available from the corresponding author per reasonable request.

\section{Acknowledgment}

This study was sponsored by Equinox Ophthalmic, Inc. (Newport Beach, CA).

\section{Disclosure}

Dr. Berdahl is the founder and CEO of Equinox Ophthalmic, Inc. Dr Berdahl reports personal fees from Alcon, Aurea Medical, Bausch and Lomb, Equinox, Glaukos, Gore, Johnson and Johnson, Kala, Kedalion, MicroOptx, New World Medical, Orasis, Oyster Point, Surface INC, Tarsus, ViaLase, Vittamed, Vance Thompson Vision, Verana Health, Visionary Ventures, and Zeiss, during the conduct of the study; personal fees from Allergan, Avedro, CorneaGen, Dakota Lions Eye Bank, Expert Opinion, Imprimis, MELT Pharmaceuticals, Ocular Surgical Data, Ocular Theraputix, Omega Ophthalmic, RxSight, Surface, INC, Tear Clear, outside the submitted work. Drs. Samuelson, Ferguson, Radcliffe, Schweitzer and Swan are consultants for Equinox Ophthalmic, Inc. Dr Lewis reports personal fees from Aerie, during the conduct of the study; personal fees from Aerie, Alcon, Allergan, Glaukos, Ivantis, MicroOptx, Zeiss, and AVS, outside the submitted work. The authors report no other conflicts of interest in this work.

\section{References}

1. Kingman S. Glaucoma is second leading cause of blindness globally. Bull World Health Organ. 2004;82:887-888. doi:10.1590/S004296862004001100019

2. Tham Y-C, Li X, Wong TY, Quigley HA, Aung T, Cheng C-Y. Global prevalence of glaucoma and projections of glaucoma burden through 2040: a systematic review and meta-analysis. Ophthalmology. 2014;121(11):2081-2090. doi:10.1016/j.ophtha.2014.05.013

3. Leske MC, Heijl A, Hussein M, Bengtsson B, Hyman L, Komaroff E. Factors for glaucoma progression and the effect of treatment: the early manifest glaucoma trial. Arch Ophthalmol. 2003;121(1):48-56. doi:10.1001/archopht.121.1.48 
4. Thompson VM, Ferguson TJ, Ahmed IIK, et al. Short-term safety evaluation of a multi-pressure dial: a prospective, open-label, nonrandomized study. Ophthalmol Ther. 2019;82(11):887-889. doi:10. 1007/s40123-019-0181-y

5. Lavia C, Dallorto L, Maule M, Ceccarelli M, Fea AM, Virgili G. Minimally-invasive glaucoma surgeries (MIGS) for open angle glaucoma: a systematic review and meta-analysis. Virgili G, ed. PLoS One. 2017;12(8):e0183142. doi:10.1371/journal.pone.0183142

6. Weinreb RN, Ong T, Sforzolini BS, Vittitow JL, Singh K, Kaufman PL. A randomised, controlled comparison of latanoprostene bunod and latanoprost $0.005 \%$ in the treatment of ocular hypertension and open angle glaucoma: the VOYAGER study. Br J Ophthalmol. 2014;99(6):bjophthalmol-2014-305908-745. doi:10.1136/bjophthalmol-2014-305908

7. Berdahl JP, Allingham RR. Cerebrospinal fluid pressure may play a role in reversal of cupping after glaucoma surgery. Am J Ophthalmol. 2009;148(4):623-4-authorreply624-5. doi:10.1016/j.ajo.2009.06.002

8. Berdahl JP, Allingham RR, Johnson DH. Cerebrospinal fluid pressure is decreased in primary open-angle glaucoma. Ophthalmology. 2008;115(5):763-768. doi:10.1016/j.ophtha.2008.01.013

9. Berdahl JP, Allingham RR. Intracranial pressure and glaucoma. Curr Opin Ophthalmol. 2010;21(2):106-111. doi:10.1097/ ICU.0b013e32833651 d8

10. Ren R, Jonas JB, Tian G, et al. Cerebrospinal fluid pressure in glaucoma: a prospective study. Ophthalmology. 2010;117(2):259 266. doi:10.1016/j.ophtha.2009.06.058

11. Liu JHK, Mansouri K, Weinreb RN. Estimation of $24 \mathrm{hr}$ intraocular pressure peak timing and variation using a contact lens sensor. Anderson MG, ed. PLoS One. 2015;10(6):e0129529. doi:10.1371/ journal.pone.0129529

12. Quigley HA, Addicks EM. Chronic experimental glaucoma in primates. II. Effect of extended intraocular pressure elevation on optic nerve head and axonal transport. Invest Ophthalmol Vis Sci. 1980;19 (2):137-152.
13. Quigley H, Anderson DR. The dynamics and location of axonal transport blockade by acute intraocular pressure elevation in primate optic nerve. Invest Ophthalmol. 1976;15(8):606-616.

14. Mader TH, Gibson CR, Pass AF, et al. Optic disc edema, globe flattening, choroidal folds, and hyperopic shifts observed in astronauts after long-duration space flight. Ophthalmology. 2011;118 (10):2058-2069. doi:10.1016/j.ophtha.2011.06.021

15. Staessen JA, Bieniaszewski L, O’Brien E, et al. Nocturnal blood pressure fall on ambulatory monitoring in a large international database. The “Ad Hoc' working group. Hypertension. 1997;29(1 Pt 1):30-39. doi:10.1161/01.hyp.29.1.30

16. De Moraes CG, Liebmann JM, Greenfield DS, et al. Risk factors for visual field progression in the low-pressure glaucoma treatment study. Am J Ophthalmol. 2012;154(4):702-711. doi:10.1016/j.ajo.20 12.04 .015

17. De Moraes CG, Jasien JV, Simon-Zoula S, Liebmann JM, Ritch R. Visual field change and $24 \mathrm{hr}$ IOP-related profile with a contact lens sensor in treated glaucoma patients. Ophthalmology. 2016;123 (4):744-753. doi:10.1016/j.ophtha.2015.11.020

18. Hoban K, Peden R, Megaw R, Halpin P, Tatham AJ. 24 hr contact lens sensor monitoring of intraocular pressure-related profiles in normal-tension glaucoma and rates of disease progression. Ophthalmic Res. 2017;57(4):208-215. doi:10.1159/000455153

19. Eklund A, Jóhannesson G, Johansson E, et al. The pressure difference between eye and brain changes with posture. Ann Neurol. 2016;80 (2):269-276. doi:10.1002/ana.24713

20. Jonas JB, Wang N, Yang D, Ritch R, Panda-Jonas S. Facts and myths of cerebrospinal fluid pressure for the physiology of the eye. Prog Retin Eye Res. 2015;46:67-83. doi:10.1016/j. preteyeres.2015.01.002
Clinical Ophthalmology

\section{Publish your work in this journal}

Clinical Ophthalmology is an international, peer-reviewed journal covering all subspecialties within ophthalmology. Key topics include: Optometry; Visual science; Pharmacology and drug therapy in eye diseases; Basic Sciences; Primary and Secondary eye care; Patient Safety and Quality of Care Improvements. This journal is indexed on PubMed

\section{Dovepress}

Central and CAS, and is the official journal of The Society of Clinical Ophthalmology (SCO). The manuscript management system is completely online and includes a very quick and fair peer-review system, which is all easy to use. Visit http://www.dovepress.com/ testimonials.php to read real quotes from published authors. 